\title{
Prospective evaluation of a decision support system providing advice on pressure support from states of over- and under-support
}

\author{
S Spadaro ${ }^{1 *}$, DS Karbing ${ }^{2}$, CA Volta ${ }^{3}$, SE Rees ${ }^{2}$ \\ From ESICM LIVES 2015 \\ Berlin, Germany. 3-7 October 2015
}

\section{Introduction}

Providing appropriate pressure support (PS) is a balance of avoiding over-support with risk of muscle atrophy and prolonged weaning, and under-support with risk of patient discomfort and stress. The Beacon Caresystem (Mermaid Care, Denmark) advises on PS using physiological models of lung mechanics, respiratory drive, acid-base status and muscle function and clinical preference functions quantifying risk of muscle atrophy, patient stress, and lung trauma. Mathematical models are tuned to measurements allowing advice to be patient specific.

\section{Objectives}

This study investigates the initial changes in pressure support from levels of over- and under-support.

\section{Methods}

Six ARDS patients residing in an ICU in Ferrara, Italy, have currently been included for this preliminary analysis. Informed consent and ethical approval was obtained. System's advice was followed for an hour from states of over- and under-support defined as $150 \%$ and $50 \%$ of baseline PS or PEEP. Average and spread are reported as mean $\pm \mathrm{SD}$.

\section{Results}

SOFA score and age were $6.2 \pm 1.9$ and $71 \pm 5$ yrs, respectively. All patients were male. Four patients were subjected to PS changes and two to PEEP changes. Figure 1 illustrates response to over- and under-support as advice and preference functions in a patient where the system advised to return PS towards baseline. Average baseline PS was $10 \pm 3 \mathrm{~cm} \mathrm{H}_{2} \mathrm{O}$. On average, Advice from PS150\% and PS50\% changed PS to $13 \pm 4 \mathrm{~cm} \mathrm{H}_{2} \mathrm{O}(114 \pm 25 \%$ baseline PS) and $6 \pm 2(57 \pm 24 \%$ baseline PS), respectively. Only a single advice on PS was provided following PEEP changes.
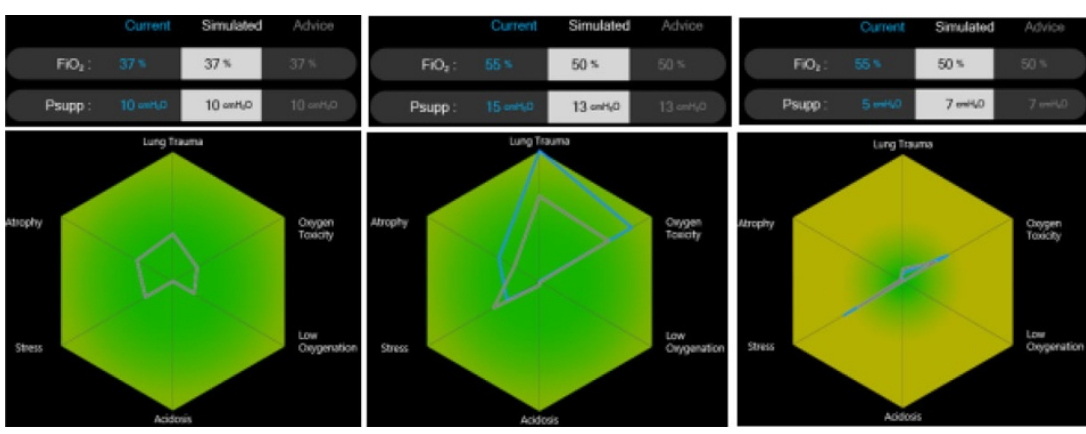

Figure 1 Advice of Beacon Caresystem.

${ }^{1}$ University of Ferrara / Intensive Care Unit, Ferrara, Italy

(0) 2015 Spadaro et al.; This is an Open Access article distributed under the terms of the Creative Commons Attribution License (http:// creativecommons.org/licenses/by/4.0), which permits unrestricted use, distribution, and reproduction in any medium, provided the original work is properly cited. 


\section{Conclusions}

These initial results indicate that Beacon Caresystem responds appropriately to over- and under-support.

\section{Grant Acknowledgment}

DSK and SER are minor shareholders and perform consultancy for Mermaid Care.

\section{Authors' details}

'University of Ferrara / Intensive Care Unit, Ferrara, Italy. ${ }^{2}$ University of Aalborg / Respiratory and Critical Care Group, Department of Health Science and Technology, Aalborg, Denmark. ${ }^{3}$ University of Ferrara / Intensive Care Unit, Morphology Surgery and Experimental Medicine, Ferrara, Italy.

Published: 1 October 2015

doi:10.1186/2197-425X-3-S1-A680

Cite this article as: Spadaro et al:. Prospective evaluation of a decision support system providing advice on pressure support from states of over- and under-support. Intensive Care Medicine Experimental 20153 (Suppl 1):A680.

\section{Submit your manuscript to a SpringerOpen ${ }^{\mathcal{O}}$} journal and benefit from:

- Convenient online submission

- Rigorous peer review

- Immediate publication on acceptance

- Open access: articles freely available online

- High visibility within the field

- Retaining the copyright to your article 